\title{
ESCRITO NAS NUVENS ${ }^{1}$
}

\section{Mariarosaria Fabris}

Dentre as inúmeras transposições da obra shakespeariana para o cinema, uma das menos lembradas é a que Pier Paolo Pasolini fez de Othello (Otelo) para realizar “Che cosa sono le nuvole?" (“O que são as nuvens?”), terceiro episódio do filme Capriccio all'italiana (Capricho à italiana, 1967) ${ }^{2}$. A apropriação do cineasta, o qual se serviu de elementos de uma obra alheia sem renunciar à sua originalidade, não é muito diferente da levada a cabo pelo próprio William Shakespeare (Ferrando, 1954, p. XIV), quando, por volta de 1604, transformou, numa de suas mais famosas tragédias, uma novela da Renascença, a partir do original em italiano ou da tradução francesa de Gabriel Chappuys (1584).

Trata-se de "Il Moro di Venezia" ("O Mouro de Veneza"), parte integrante de Gli ecatommiti (1565), escrita por Giovambattista Giraldi Cinzio ${ }^{3}$, tendo provavelmente como fonte a história de Cristoforo Moro - lugar-tenente em Chipre, que, ao regressar a Veneza, em 1508, perdeu sua esposa na viagem — ou a de Francesco da Sessa,

\footnotetext{
${ }^{1}$ Este trabalho nasceu de dois encontros casuais. O primeiro, por volta de 2009, foi com o artigo "Otelo, uma tragédia construída sobre uma estrutura cômica", na livraria do cine Arteplex do Rio de Janeiro, cuja leitura me levou a pensar se, em "Che cosa sono le nuvole?", Pasolini havia seguido ou não pelo caminho apontado por Barbara Heliodora. O segundo, em 2010, na Livraria Cultura do Recife, com a tradução brasileira de "O mouro de Veneza", de Giovambattista Giraldi Cinzio, que chamou a minha atenção, tornando mais aguda a vontade de trabalhar com o episódio pasoliniano. Um trabalho à margem de minhas investigações, mas não de minha curiosidade. Boa parte da pesquisa para redigi-lo foi realizada, entre 2011 e 2012, na biblioteca do Museu Lasar Segall, a cujos funcionários, sempre solícitos e atenciosos, eu gostaria de agradecer.

${ }^{2}$ “Che cosa sono le nuvole?" deveria ter constituído o segundo episódio de Che cos'è il cinema? [O que é o cinema?] ou Smandolinate [Bandolinadas, ou antes, composições poéticas melosas e amaneiradas], filme que Pasolini não conseguiu realizar. O diretor refere-se a este projeto, no prólogo do episódio, ao focalizar os cartazes das quatro partes que o comporiam - "La terra vista dalla luna" ("A terra vista da lua"), que integrou Le streghe (As bruxas, 1966), "Che cosa sono le nuvole?", "Le avventure del re magio randagio" [As aventuras do rei mago errante] e "Mandolini" [Bandolins] -, todas interpretadas por Totò (Aumont 2006, p. 188-189). Enquanto no primeiro cartaz, já rasgado e jogado no chão, está escrito "ontem", os demais anunciam os espetáculos para "hoje", "amanhã" e em "breve", respectivamente. Os cartazes reproduzem quadros de Diego Velázquez: o de "Che cosa sono le nuvole?" é um detalhe de Las meninas (As meninas, 1656).

${ }^{3}$ Coletânea de 113 novelas (e não 100, como o título, de derivação grega, levaria a crer), inspirada na estrutura do Decameron (Decamerão, c. 1348-1353), de Giovanni Boccaccio. De outra novela de Gli ecatommiti, Shakespeare extraiu a comédia Measure for measure (Medida por medida, 1604) (Fubini 1947).
} 
alcunhado "o capitão mouro", o qual, preso em Chipre entre 1544 e 1545, foi enviado para Veneza por um crime não especificado (Praz, 1948, p. 337).

Não é improvável que Pasolini tenha lido a novela de Cinzio, mas, ao concretizar seu projeto, aproveita a popularidade que a história havia adquirido na versão shakespeariana. Em sua adaptação cinematográfica, os cinco atos foram reduzidos a algumas cenas que sintetizam a trama: Iago (Totò) odeia Otelo (Ninetto Davoli), porque este, em vez dele, nomeou Cássio (Franco Franchi) seu tenente; em sua vingança contra os dois, envolve Rodrigo (Ciccio Ingrassia), atraído por Desdêmona (Laura Betti), mulher do nobre mouro ${ }^{4}$. Os personagens principais foram mantidos e, além dos já citados, aparecem ainda Bianca, a amante de Cássio (Adriana Asti, apenas uma presença cênica), Brabâncio, o pai de Desdêmona (Carlo Pisacane, que tem direito a uma única deixa), e três soldados. A ação desenrola-se em Veneza e em Chipre, mas a passagem de um espaço a outro se dá pela fala ${ }^{5}$, como na cena elisabetana, na qual o cenário não importava, pois o palco era o Theatrum Mundi, como assinala Jan Kott (1965, p. 113).

O cineasta reduziu a trama ao essencial para concentrar-se no sentimento da inveja que guia as ações de Iago em relação a Otelo e nas hesitações do Mouro ${ }^{6}$. Não por acaso aquele personagem surge em cena com o rosto pintado de verde, cor que, em

\footnotetext{
${ }^{4}$ Por exemplo, do III ato foram eliminadas as cenas 1 e 2, enquanto da 3 se manteve o encontro entre Cássio e Desdêmona, mas sem a presença de Emília, mulher de Iago. No filme, há certo interesse de Desdêmona pela beleza e juventude de Cássio, mas as insinuações de Iago sobre a "traição" são mais sintéticas e, muitas vezes, confiadas a expressões faciais ou a gestos. Além do mais, é Iago e não sua esposa quem encontra o lenço, por acaso, e o entrega a Rodrigo, personagem cujo papel se torna maior com a supressão de Emília.

${ }^{5}$ É interessante notar que, em 1966, Pasolini esboça sete tragédias, que terminará em anos sucessivos, nas quais começa a expor o conceito de "teatro di Parola" (teatro da Palavra), como ele o denomina, lançando o "Manifesto per un nuovo teatro" ("Manifesto por um novo teatro"). Ao opor-se tanto ao teatro tradicional quanto ao experimental, Pasolini, inspirando-se nas tragédias gregas, propõe que, para valorizar o texto, a ação cênica seja praticamente anulada, de modo que a Palavra possa consubstanciar-se por intermédio do ator. (Fabris, 2011). Para Alberto Moravia (2010, p. 1172) também, as tragédias gregas, ao lado das peças shakespearianas, são o contrário dos textos dramáticos de um Luigi Pirandello ou de um Jean-Paul Sartre, baseados na ação e não na escrita: "Aqui tudo acontece na escrita; a representação não se destina a completar o texto, mas apenas a interpretá-lo". Como escreveu recentemente Christophe Bident (2013), é importante escutar o texto, deixando todos os significados em aberto, para dar corpo e construir o imaginário de uma obra.

${ }^{6}$ “O verdadeiro criador da tragédia é Iago, sem o qual Otelo continuaria a viver em paz com sua Desdêmona. Mas a primeira condição para que aconteça a tragédia, ou seja, a crítica, é a paixão do Mouro", sublinha Moravia (2010, p. 1450-1451). Para o escritor, o que alimenta a fantasia do alferes é a paixão do casal, é o ciúme que ele nutre por seu superior, fato que revela uma postura de "dependência, passividade, esterilidade".
} 
italiano, além de designar sentimentos intensos, pode referir-se a fortes emoções, como a que se manifesta na expressão verde d'invidia, no sentido de roer-se de inveja ${ }^{7}$.

A caracterização dos personagens remete à commedia dell'arte, com seus tipos fixos — os enamorados (Otelo e Desdêmona; Cássio e Bianca), o marido ciumento (Otelo), o pai severo (Brabâncio), o alcoviteiro (Iago), o tolo (Rodrigo) —, em que figurinos, gestos, impostação da fala cênica e desempenho dramático eram quase sempre cristalizados (Fabris, 2003).

No episódio de Pasolini, essas máscaras são interpretadas por atoresque deveriam atuar como marionetes, uma vez que são dotados de fios. ${ }^{8} \mathrm{O}$ teatro de marionetes, em seu parentesco com a commedia dell'arte, também apresenta tipos fixos, frequentemente caracterizados como máscaras. ${ }^{9}$ Desse modo, o diretor vale-se de duas formas populares de espetáculo — que sobrepõe — para dar vida a seus personagens. É interessante notar que, em termos de um teatro mais popular, na Itália do fim do século XIX eram comuns espetáculos em que atores passavam a substituir bonecos de madeira. O escritor Giovanni Verga havia registrado esse fenômeno numa novela escrita em 1890 "Don Candeloro e C.i”, dentre várias outras que dedicou à arte de representar (que integram a coletânea Don Candeloro e C.i, 1893), em que o dono de um teatro de marionette parlanti (marionetes falantes) é obrigado a adaptar-se aos novos tempos para sobreviver:

Agora, nos pequenos teatros de marionetes atuavam personagens de carne e osso, a História de Garibaldi, imaginem, e também aquelas farsas de Polichinelo; e neles

\footnotetext{
${ }^{7}$ Ao traçar um paralelo entre Iago e o criado da commedia dell'arte (Zanni, Arlequim ou Briguela), antes servindo seus próprios interesses do que os do amo, Barbara Heliodora (1987, p. 3) recorda a descrição do "sombrio e cruel Brighella", feita em 1956 por Thelma Niklaus, que coincide com a caracterização que Pasolini faz de Iago: "sua máscara, de um pobre verde amarelado, dava-lhe a expressão cínica de um homem para o qual a vida não reservava mais surpresas... sua desabusada segurança carregava-o vitoriosamente por sua carreira de vigarista ou valentão de aluguel. Era o intermediário, o fanfarrão, o espião, sub-reptício e sinistro em suas andanças, jamais pressagiando nada de bom para quem entra em contato com ele, sempre pronto a vender sua honra, seu amo... Tinha prazer selvagem em derrotar amigo ou inimigo, em trazer problemas, em cometer crimes". Segundo Jacques Aumont (2006, p. 189), na caracterização de Iago, com seu "rosto pintado de verde, encimado por um imenso chapéu preto", Pasolini ter-se-ia inspirado em pinturas de Masolino ou Paolo Uccello. Não podemos esquecer, no entanto, que, na própria peça, há referência à cor verde. Moacyr Scliar (2005, p. 133), ao asseverar que "ciúme e inveja são farinha do mesmo saco", lembra que Iago define o ciúme "o monstro de olhos verdes" (Shakespeare, 2010, p. 86), expressão que o bardo de Avon já havia empregado em The merchant of Venice ( $O$ mercador de Veneza, c. 1596) para designar a inveja.

${ }^{8}$ Como assinala Vittorio Podrecca (1951, p. 357), o repertório do teatro de marionetes, ao incorporar obras de grandes escritores, dentre os quais Shakespeare, ajudou a popularizá-las.

${ }^{9}$ George Speaight (1955, p. 28) e Henryk Jurkowski (1996, p. 104) observam que, na commedia dell'arte, atuavam seja atores, seja marionetes, ao mesmo tempo.
} 
cantavam mulheres seminuas, que transformavam o palco num monturo. [...] A fim de não atuar para os bancos vazios, havia chegado ao ponto de deixar entrar de graça velhos clientes, fiéis às belas Histórias de Orlando e dos antigos Paladinos [...].(Verga, 1978, p. 219-220)

As marionetes falantes de Pasolini, aparentemente, têm seus atos determinados por um manipulador (Francesco Leonetti); no entanto, ele é antes alguém que auxilia na condução da trama do que propriamente um deus ex machina, aquele que, ao desatar os nós (Forestier, 2008), permitiria extrair um significado maior do que está sendo representado (no palco, na tela e na vida), ${ }^{10}$ como depreendemos de uma troca de ideias que tem com o nobre mouro e seu alferes. Ao ouvir as queixas de Otelo, que não se conforma com o fato de ser um assassino e de sujeitar-se a Iago, diz o marionetista: "Talvez porque, na verdade, seja você quem quer matar Desdêmona"- e, diante do espanto do interlocutor, prossegue: "Talvez porque Desdêmona goste de ser morta"11, quase a lembrar que o nome da heroína vem do grego dusdàimon, e significa a desditada, a que nasceu sob uma má estrela (Praz, 1952).

Há, portanto, um destino a ser cumprido até o fim, contra o qual se choca o livre arbítrio dos homens. Otelo, no entanto, parece não se conformar e indaga: "Mas qual é a verdade? É o que eu penso de mim, ou o que pensam as pessoas, ou o que pensa aquele lá dentro?". E passa a senti-la, embora abafada dentro de si, quando Iago lhe sugere que se concentre: “Aquela é a verdade. Mas, psss... não deve nomeá-la, porque, assim que a nomear, ela não existe mais". A verdade interior não consegue ser expressa pelas palavras e, assim, cada um passa a ser construído pelo discurso dos outros, e a vida torna-se uma ficção (Mariniello, 1999, p. 246-247), como já havia apontado Luigi Pirandello, ao abordar a impossibilidade de existir para além de um espaço de representação social (Budor, 1991).

Nessas conversas nas coxias ou quando Otelo, fora de cena, observa Iago dizer a Rodrigo como pretende atiçar seus ciúmes, Pasolini se afasta das manifestações teatrais populares e dialoga com o teatro de Bertolt Brecht, em virtude do estranhamento que

\footnotetext{
${ }^{10}$ Moravia (2008, p. 166-167, 273), no romance L'attenzione (1965), chega a identificar o deus ex machina com a morte, o que se coaduna com as teorias pasolinianas sobre cinema. No ensaio "Il cinema di poesia" ("O cinema de poesia", 1965), Pasolini (1966) afirma que, num filme, a vida se reproduz no plano-sequência, cujo fluxo contínuo de imagens é interrompido pelo corte, corte este que, porém, lhe dá significado, assim como a morte dá um sentido à trajetória humana.

${ }^{11}$ As falas foram extraídas diretamente do episódio pasoliniano.
} 
essas inserções insólitas provocam nos espectadores, levando-os a uma fruição crítica e não a uma identificação.

Há ainda o comportamento das marionetes, que, ao atuarem como numa peça do teatro épico brechtiano, estabelecem uma distância em relação aos personagens que estão interpretando (Ivernel 2008). O diretor, no entanto, não deixa de ser fiel também ao espírito do bardo inglês, se lembrarmos que, segundo Anthony Burgess (2006, p. 92), o ator shakespeariano tentava "estabelecer uma intimidade com essa plateia, envolvê-la na peça, e seus solilóquios não são falas em que o ator finge estar se dirigindo a si mesmo, mas, comunicações íntimas com a plateia"12. De fato, os monólogos de Iago e de Otelo nos bastidores são momentos reveladores do que se passa no íntimo das marionetes quando elas deixam de ser os personagens que estão interpretando.

E o episódio pasoliniano tem duas plateias: a que está vendo o filme e, dentro deste, a que está assistindo ao teatro de marionetes, um público participativo, que aplaude, vaia, reage rumorosamente aos atos do alferes e do Mouro e invade o palco, quando este tenta matar a esposa, situações em que o episódio resvala para a comédia pastelão $^{13}$.

Nesse aspecto, também, Pasolini estaria próximo de Shakespeare, embora pelo avesso: ele empresta a uma obra trágica um tom de comédia, enquanto o autor inglês baseou sua tragédia numa estrutura cômica, como aponta Barbara Heliodora (1987), ao elencar os elementos da commedia dell'arte incorporados à feitura de Othello: cenário (Veneza); composição das cenas; caracterização dos personagens; improvisação constante diante de novas situações; conversas de duplo sentido; perda do lenço e suas consequências; desmoralização do marido traído; desenrolar da trama, com Iago como condutor, ou seja, como "responsável pelo desenvolvimento mecânico das intrigas", ao contar "histórias críveis às pessoas com maior possibilidades de acreditar nelas". ${ }^{4}$

\footnotetext{
${ }^{12}$ É escusado dizer que Shakespeare era uma referência importante para Brecht (Mostaço, 2007, p. 15-16).

${ }^{13}$ Para alguns críticos, dentre os quais Aumont (2006, p. 192), a invasão do palco por parte do público seria uma retomada do que acontece no teatro de marionetes no segundo episódio de Paisà (Paisá, 1946), de Roberto Rossellini, a quem Pasolini estaria prestando uma homenagem. Hervé Joubert-Laurencin (1995, p. 120-121) aponta, como matriz dessas sequências nos dois filmes, o décimo capítulo de Le avventure di Pinocchio (As aventuras de Pinóquio, 1883), de Carlo Collodi, no qual o boneco de madeira vai assistir a um espetáculo de marionetes. Estas, ao reconhecerem em Pinóquio um seu semelhante, bagunçam a representação e o boneco, depois de subir no palco, é levado em triunfo (Collodi, 2011, p. 57-60).

${ }^{14}$ A autora lembra ainda que os dramaturgos elisabetanos conheciam bem a commedia dell'arte. Shakespeare, que deve ter tido ocasião de assistir a esse tipo de espetáculo em 1602, pagou seu tributo à arte teatral italiana também nas comédias que escreveu.
} 
Em que pesem os momentos mais descontraídos, o episódio pasoliniano não deixa de ser trágico, pois o centro da ação dramática é o conflito interior do protagonista; no entanto, se, em Othello, a tragédia "não é provocada, como no teatro grego, pelo choque entre forças inimigas em contraste entre si ou pela vontade cega do fado, mas é a consequência necessária de um momento de fraqueza que empurra fatalmente para o delito e traz consigo sua expiação" (Ferrando, 1954, p. XXI), em "Che cosa sono le nuvole?", a marionete Otelo tem que interpretar seu papel até o fim, como foi predeterminado, apesar de sua revolta.

Como se deduz dos papos nos bastidores, mesmo sem se desfazerem de suas máscaras, Otelo e Iago (como os demais bonecos) têm um pensamento próprio, refletem sobre o que estão representando, embora saibam que seu destino é guiado por uma entidade superior cujos ditames nem sempre entendem. Destruídas pelo público, as duas marionetes são jogadas fora e levadas por um lixeiro (Domenico Modugno), enquanto as demais, enfileiradas nas coxias, lamentam a sorte que cabe a todos eles, pelo fato de existirem, como Cássio observa desolado.

Durante a despedida e o transporte dos bonecos até o lixão, torna a surgir a música cantada no início do episódio por Modugno (autor da melodia), na qual Pasolini praticamente recupera o motivo do amor, traduzindo em imagens, desta vez verbais, o texto shakespeariano:

\author{
Que eu possa me danar \\ se não a amo \\ e se assim não fosse \\ não entenderia mais nada. \\ Todo o meu louco amor \\ sopram-no os céus \\ sopram-no os céus assim"15.
}

Esses primeiros versos são praticamente uma reescrita de deixas de Otelo na cena 3 do III ato: "Que a perdição tome conta de minha alma, mas eu te amo! E quando

\footnotetext{
${ }^{15}$ A letra da canção, de autoria de Pasolini, foi extraída diretamente de "Che cosa sono le nuvole?". Reproduzimos a versão original: Ch'io possa esser dannato / se non ti amo / e se così non fosse / non capirei più niente. / Tutto il mio folle amore / lo soffia il cielo / lo soffia il cielo così. // Ah, malerba soavemente delicata / di un profumo che dà gli spasimi. / Ah, ah, tu non fossi mai nata! / Tutto il mio folle amore / lo soffia il cielo / lo soffia il cielo così. // Il derubato che sorride / ruba qualcosa al ladro, / ma il derubato che piange / ruba qualcosa a se stesso, / perciò io ti dico, finché sorriderò / tu non sarai perduta. // Ma queste son parole / che non ho mai sentito / e un cuore, un cuore affranto / si cura con l'udito. / E tutto il mio folle amore / lo soffia il cielo / lo soffia il cielo così.
} 
não mais te amar, o caos se estabelecerá uma vez mais."; “todo o meu amor apaixonado, assim eu o sopro aos céus..." (Shakespeare, 2010, p. 82 e 98);
Ah, erva daninha suavemente delicada de um perfume que causa espasmos. $\mathrm{Ah}$, antes você não tivesse nascido! Todo o meu louco amor sopram-no os céus sopram-no os céus assim.

A terceira estrofe traduz a seguinte deixa de Otelo na cena 2 do IV ato: “Ah, tu, erva daninha, tão amavelmente linda, tão docemente perfumada, tanto que os cinco sentidos sofrem perante tua pessoa, quisera eu nunca tivesse nascido!” (p. 128);
Quem foi roubado e sorri rouba algo ao ladrão, mas quem foi roubado e chora rouba algo a si mesmo, por isso lhe digo, até que eu sorrir você não estará perdida.

Nesses versos, ecoam as seguintes deixas de Otelo e Iago, respectivamente, na cena 3 do III ato:

Que noção tinha eu de suas horas roubadas de luxúria? Eu não enxergava, não pensava sobre isso, e isso não me doía. Eu dormia bem a cada noite, alimentava-me bem, era feliz. Eu não encontrava nos lábios dela os beijos de Cássio. Digo isto de quem foi roubado e não deu por falta da coisa subtraída: deixe-o ignorante do roubo, e ele nem terá sido roubado. [...]

O bom nome de um homem e de uma mulher, meu prezado senhor, é a jóia mais pessoal de suas almas. Quem rouba minha bolsa rouba um lixo... é alguma coisa, um nada: foi meu, agora é dele, e já foi possessão de milhares de pessoas. Mas aquele que vem me lesar em meu bom nome estará subtraindo de mim aquilo que não faz dele pessoa rica mas que me torna verdadeiramente pobre. (p. 93; 85-86).

E, por fim:

Mas essas são palavras que nunca escutei e um coração alquebrado cura-se pelo ouvido.

E todo o meu louco amor sopram-no os céus sopram-no os céus assim. 
O coração de Otelo só poderia sossegar se ele, confiando no amor de Desdêmona (e na amizade de Cássio), não prestasse atenção ao que Iago ia insinuando sobre o comportamento dela (e do tenente). É pelo ouvido que o alferes envenena o espírito do Mouro, a ponto de levá-lo a ver o que ele queria que o outro visse. A penúltima estrofe pode ser confrontada com as seguintes deixas de Iago, na terceiras cenas do I e II atos, respectivamente:

Agora, deixa-me ver: pegar o lugar dele e coroar minha vontade com dupla patifaria. Mas, como? Como? Vejamos: após algum tempo, maltratar os ouvidos de Otelo, sugerindo que Cássio é por demais íntimo de sua mulher, que ele tem uma figura e uma disposição meiga suspeitáveis... moldado para fazer das mulheres pessoas falsas. [...]

Enquanto esse honesto otário importuna Desdêmona com seus pedidos para que ela conserte seu destino, e, enquanto ela, por ele, implora clemência ao Mouro, eu estarei vertendo esta pestilência nos ouvidos de nosso general: que ela o quer de novo nas boas graças de seu superior para apaziguar a luxúria de seu corpo. ( p. 41, 72)

A música, que marca o prólogo e o epílogo, vem emoldurar a diegese propriamente dita: o "nascimento" de um novo boneco, seu itinerário no palco (da vida), sua morte e sua descoberta de um significado maior para a aventura humana. Ao optar pela representação dentro da representação, Pasolini acaba por engendrar um filme de uma refinada tessitura intertextual, pois além de obras teatrais e cinematográficas, na base desse projeto há também a contribuição da pintura, com a presença de quadros de Diego Velázquez que remetem à noção de imagem especular - Venus del espejo (Vênus ao espelho, 1650) ${ }^{16}$ - e de perspectiva abismal — Las meninas.

E assim, a ideia de que viver é uma representação ou consiste em estarmos "num sonho dentro de um sonho" (ao que tudo indica, sonhado por outrem, pelo deus ex machina do universo), expressa com amargor por Iago nos bastidores para consolar Otelo inconformado com o fato de ser diferente de como se imaginava, ganha maior consistência. A derivação dessa concepção do que seja a vida — uma ilusão, um jogo de espelhos (Ramos, 2011) ou o eterno contraste entre o Criador e a criatura (Sesé, 1991, p. 144) - é evidente: L'illusion comique (A ilusão cômica, 1636), de Pierre Corneille ${ }^{17}$, de um lado, e, de outro, La vida es sueño (A vida é um sonho, 1635), de Pedro Calderón

\footnotetext{
${ }^{16}$ Esta obra é vislumbrada na cabine do caminhão que transporta as duas marionetes, no epílogo do episódio.

${ }^{17}$ Luiz Fernando Ramos (2011) lembra que, nesta peça, Corneille se aproxima de Shakespeare e dialoga com a commedia dell'arte.
} 
de la Barca $^{18}$, a partir da qual, nesse mesmo período, Pasolini começa a engendrar a peça Calderón ${ }^{19}$.

Menos evidente, talvez, seja a derivação do título do episódio, ${ }^{20}$ aquelas belas e indecifráveis nuvens que Otelo e Iago descobrem quando são atirados no lixão, ou melhor, lançados no Báratro ${ }^{21}$. Ao levarem Iago a exclamar "Ah, torturante e maravilhosa beleza da Criação! Ah!”, as nuvens representam a teofania ${ }^{22}$, são as deusas celestes que oferecem aos homens "o saber, a dialética, o entendimento, a linguagem elevada e verbosa, a arte de comover e enganar", como diz Sócrates, na obra de Aristófanes $\left(1995\right.$, p.32) ${ }^{23}$. A comédia As nuvens, representada pela primeira vez em Atenas em 423 a.C., tinha servido para reforçar as acusações de ateísmo movidas contra o filósofo grego (Kury, 1995, p. 106), que teria substituído os deuses míticos pelas divindades celestes, "símbolo das extravagantes e inconsistentes especulações

\footnotetext{
${ }^{18}$ Não podemos esquecer que, embora com certa parcimônia, Shakespeare também recorreu à perspectiva abismal. Ademais, fez uso do "espetáculo involuntário", da "manipulação", ou seja, do "inverso maléfico da ilusão", o qual em Othello, por exemplo, leva o protagonista a tomar a felicidade amorosa expressa por Cássio como a prova cabal da infidelidade de Desdêmona (Lecocq \& Treilhou-Balaudé 1991, p. 1259).

${ }^{19}$ Para Joubert-Laurencin (1995, p. 122), em Calderón (1967), ao nomear todos os protagonistas de Las meninas, Pasolini demonstra não só conhecer bem a obra de Velázquez, como ter lido Les mots et les choses (As palavras e as coisas, 1966), em que Michel Foucault analisava o quadro. Segundo Silvestra Mariniello (1999, p. 244-245), o diretor se vale da leitura da obra do filósofo francês também em "Che cosa sono le nuvole?".

${ }^{20}$ Não parece nem um pouco provável, além de ser bastante simplista, a hipótese aventada por JoubertLaurencin (1995, p. 117) de que o título do episódio teria sido escolhido porque permitia estabelecer uma relação entre as nuvens do filme e o céu da canção Nel blu dipinto di blu (mais conhecida como Volare), sucesso mundial de Modugno, em 1958. Ademais, o compositor já havia colaborado com Pasolini, ao cantar os créditos de Uccellacci e uccellini (Gaviões e passarinhos, 1966), nos quais, além de dados técnicos e da definição do gênero da obra, tecia um comentário sobre os intérpretes dos dois protagonistas, Totò e Ninetto Davoli (Fabris 1999).

${ }^{21}$ Precipício localizado em Atenas, no qual eram atirados os condenados à morte (Kury, 1995, p. 107). Segundo Joubert-Laurencin $(1995,123)$, essa sequência, com os dois corpos inertes sendo transportados num caminhão e, em seguida, atirados numa vala, remeteria a Auschwitz, interpretação que resulta algo forçada.

${ }^{22}{ }^{2}$ como se as marionetes conseguissem voltar a um estado de inocência, que o homem perdeu a "partir do momento em que tem consciência de si, o que põe sobre cada ação um suposto olhar que julga se ela é certa ou errada, se deve ou não ser feita" (Süssekind, 1997, p. 49), como se depreende das conversas nos bastidores. O "silêncio transcendente" que está prestes a substituir as palavras, ou seja, aquele "estado de maravilhamento" (Hebmüller, 2013, p. 12) diante da obra suprema,que encerra o episódio, está ligado à cultura católica dentro da qual o marxista Pasolini foi criado. O diretor aprofundará a questão da manifestação divina em Teorema (1968) e no romance homônimo que derivou do filme (Fabris, 2002).

${ }^{23} \mathrm{~A}$ respeito disso, Aumont (2006, p.189) propõe outra leitura, quando compara o episódio a Francesco giullare di Dio (Francisco, arauto de Deus, 1949), "com os seus quatro ou cinco planos de nuvens em fondu e o seu fondu ao negro final, que é um absoluto. As nuvens de Rossellini eram céu, eram o signo visível do sobrevisível; fazer um fondu ao negro era fechar as pálpebras do cinema para que só víssemos o Paraíso. Pasolini traz-nos de volta à terra, ao único mundo que existe, para sempre. A partir de então, a conclusão de seus filmes será sempre abrupta, deixar-nos-á sempre no meio das coisas, da pungente beleza da criação, da crueldade do mundo com o qual se harmoniza um pouco de inocência". A comparação entre os dois filmes, no entanto, parece apontar antes que Pasolini seguiu na esteira de Rossellini.
} 
filosóficas" (Brambilla, 1948). Pasolini, ao ler a peça em chave inversa à proposta pelo autor, faz triunfar o pensamento de Sócrates ${ }^{24}$, que havia eleito três divindades, "o Caos, as Nuvens e a Língua" (Aristófanes, 1995, p. 40) para presidirem o destino dos homens ${ }^{25}$.

Na tragédia shakespeariana, segundo Jan Kott (1965, p. 114-115): “As questões fundamentais, relativas ao sentido ou ao absurdo do mundo, só podem ser destrinchadas no fim da viagem. Lá embaixo, exatamente, no fundo do abismo”. O mesmo acontece em "Che cosa sono le nuvole?". Se Othello "é a tragédia do homem sob um céu vazio" (Kott, 1965, p. 114), ou sob um "distante céu de mármore”, como afirma o protagonista (Shakespeare, 2010, p. 98), no episódio engendrado por Pasolini, as personagens, ao se depararem com um céu povoado de nuvens, descobrem o sentido do sagrado cósmico e, com ele, o significado da vida.

\section{Referências}

Aristófanes. As nuvens; Só para mulheres; Um deus chamado dinheiro. Trad. Mário da Gama Kury. Rio de Janeiro: Zahar, 1995.

AUMONT, Jacques. O rasgão - Che cosa sono le nuvole? Trad. Antonio Rodrigues e Rui Santana Brito. In: RODRIGUES, Antonio (Org.). Pier Paolo Pasolini: o sonho de uma coisa. Lisboa: Cinemateca Portuguesa-Museu do Cinema, 2006, p. 186-195.

Barbara Heliodora. Otelo, uma tragédia construída sobre uma estrutura cômica. Cadernos de Teatro. Rio de Janeiro, n. 112, jan.-fev.-mar., p. 1-7, 1987 [texto publicado posteriormente em Barbara Heliodora. Falando de Shakespeare. São Paulo: Perspectiva, 2007, p. 275-285].

BIDENT, Christophe. La realpolitik selon Shakespeare. Le Magazine Littéraire, Paris, n. 529, p. 14, 2013.

BRAMBILLA, Arturo. Nuvole. In: Dizionario letterario Bompiani delle opere e dei personaggi di tutti i tempi e di tutte le letterature. Milano: Bompiani, 1948, v. V, p. 154.

\footnotetext{
${ }^{24}$ Defensor do bom senso tradicional, Aristófanes não aceitava as sutilezas da dialética e da retórica socráticas (Brambilla, 1948).

${ }^{25}$ Como já acenamos na nota5, é nesse período que Pasolini torna a debruçar-se sobre a dramaturgia grega, interesse que se explicita nas peças e nos filmes produzidos até o fim dos anos 1960 (Fabris, 2009).
} 
BUDOR, Dominique. Luigi Pirandello. In: CORVIN, Michel (Org.). Dictionnaire encyclopédique du théâtre à travers le monde. Paris: Bordas, 1991, p. 654-655. BURGESS, Anthony. William Shakespeare. In: A literatura inglesa. Trad.

Duda Machado. São Paulo: Ática, 2006, p. 89-99.

CINZIO, Giovambattista Giraldi. O mouro de Veneza. In: WATAGHIN, Lucia (Org.). Romeu e Julieta e outros contos renascentistas italianos. Trad. Nilson Moulin. Rio de Janeiro: Imago, 1996, p. 63-74.

COLLODI, Carlo. Le avventure di Pinocchio. Milano: Piemme, 2011.

FABRIS, Mariarosaria. Comédias de máscaras. In: SCALA, Flaminio. A loucura de Isabella e outras comédias da commedia dell'arte. Trad. Roberta Barni. São Paulo: Iluminuras, 2003, p. 13-14.

. Um encontro frustrado. Revista Italiano UERJ, v. 2, n. 2, p. 6-16, 2011.

. O nome do pai. Teorema - Crítica de Cinema, n. 1, p. 5-6, 2002.

. Pasolini no rumo de Brecht. Sinopse, p. 28-29, jun. 1999.

. A tragédia grega no cinema de Pier Paolo Pasolini. In: CORSEUIL, Anelise Reich et alii (Org.). Cinema: lanterna mágica da história e da mitologia. Florianópolis: Editora da UFSC, 2009, p. 117-140.

FERRANDO, Guido. Introduzione. In: SHAKESPEARE, William. Coriolano. Firenze: Sansoni, 1954, p. V-XXXIX.

FORESTIER, Georges. Deus ex machina. In: CORVIN, Michel (Org.). Dictionnaire encyclopédique du théâtre à travers le monde. Paris: Bordas, 2008, p. 421.

FUBINI, Mario. Gli ecatommiti. In: Dizionario letterario Bompiani delle opere e dei personaggi di tutti i tempi e di tutte le letterature. Milano: Bompiani, 1947, v. III, p. 6-7.

HEBMÜLLER, Paulo. Na presença do Desconhecido. Jornal da USP, ano XXVIII, n. 999, p. 12-13, 20-26 maio 2013.

IVERNEL, Philippe. Bertolt Brecht; Effet de distanciation; Le théâtre épique. In: CORVIN, Michel (Org.). Dictionnaire encyclopédique du théâtre à travers le monde. Paris: Bordas, 2008, p. 218-220; 439; 501.

JURKOWSKI, Henryk. A history of European puppetry from its origins to the end of the century. Lewiston-Queenstone-Lampeter: The Edwin Mellen Press, 1996.

JOUBERT-LAURENCIN, Hervé. Pasolini: portrait du poète en cinéaste. Paris: Cahiers du Cinéma, 1995. 
KOTT, Jan. Shakespeare notre contemporain. Paris: Marabout, 1965.

KURY, Mário da Gama. Notas. In: Aristófanes. As nuvens; Só para mulheres; Um deus chamado dinheiro. Rio de Janeiro: Zahar, 1995, p. 104-107.

LECOCQ, Louis; TREILHOU-BALAUDÉ, Catherine. William Shakespeare. In: CORVIN, Michel (Org.). Dictionnaire encyclopédique du théâtre à travers le monde. Paris: Bordas, 1991, p. 1255-1261.

MARINIELlO, Silvestra. Pier Paolo Pasolini. Madrid: Cátedra, 1999.

MORAVIA, Alberto. L’attenzione. Milano: Bompiani, 2008.

Otello e Iago ovvero Una mattina di malumore; Sotto il segno di Baffone. In: .Cinema italiano: recensioni e interventi 1933-1990. Milano: Bompiani, 2010, p. 1449-1453; 1171-1174.

MOSTAÇO, Edelcio. Brecht, o organon da diversão. ArtCultura, v. 9, n. 15, p. 7-16, jul.-dez. 2007.

PASOLINI, Pier Paolo. A poesia do cinema novo. Revista Civilização Brasileira, v. 1, n. 7, p. 267-287, maio 1966.

PODRECCA, Vittorio. Marionetta. In: Enciclopedia italiana di scienze, lettere ed arti. Roma: Istituto della Enciclopedia Italiana, 1951, v. XXII, p. 356-357.

PRAZ, Mario. Desdemona. In: Dizionario letterario Bompiani delle opere e dei personaggi di tutti i tempi e di tutte le letterature. Milano: Bompiani, 1952, v. VIII, p. 225.

PRAZ, Mario et alii. Otello, il Moro di Venezia. In: Dizionario letterario Bompiani delle opere e dei personaggi di tutti i tempi e di tutte le letterature. Milano: Bompiani, 1948, v. IV, p. 337-339.

RAMOS, Luiz Fernando. Corneille faz reflexão sobre a representação da vida. Folha de S. Paulo, São Paulo, 26 out. 2011.

SCLIAR, Moacyr. Ciúme: o normal e o patológico. In: O olhar médico: crônicas de medicina e saúde. São Paulo: Ágora, 2005, p. 133-135.

SESÉ, Bernard. Calderón de la Barca. In: CORVIN, Michel (Org.). Dictionnaire encyclopédique du théâtre à travers le monde. Paris: Bordas, 1991, p. 143-144.

SHAKESPEARE, William. Otelo. Trad. Beatriz Viégas-Faria. Porto Alegre: L\&PM, 2010.

SPEAIGHT, George. The history of the English puppet theatre. London: Harrap, 1955. 
SÜSSEKIND, Pedro. O mundo em forma de anel. In: KLEIST, Heinrich von. Sobre o teatro de marionetes. Rio de Janeiro: Sette Letras, 1997, p. 43-52.

VERGA, Giovanni. Don Candeloro e C.i. In: Tutte le novelle. 2 v. Milano: Mondadori, 1978, v. 2, p. 215-222. 